\title{
Accurate Measurement of Chromium Isotopic Compositions in Geological Reference Materials by Double-Spike MC-ICP-MS
}

\author{
Kai Shi, ${ }^{\mathrm{a}}$ Guangliang Wu, ${ }^{\mathrm{a}}$ Jian-Ming Zhu, ${ }^{\mathrm{a}, *}$ and Xiangli Wang ${ }^{\mathrm{b}, \mathrm{c}}$ \\ ${ }^{a}$ State Key Laboratory of Geological Processes and Mineral Resources, China University of Geosciences (Beijing), Beijing 100083, P.R. China. \\ ${ }^{\mathrm{b}}$ Department of Marine Sciences, University of South Alabama, Mobile, AL36688, USA. \\ ${ }^{\mathrm{c}}$ Dauphin Island Sea Lab, Dauphin Island, AL 36528, USA.
}

Received: December 27, 2020; Revised: February 3, 2021; Accepted: February 3, 2021; Available online: February 4, 2021.

DOI: $10.46770 / A S .2021 .008$

ABSTRACT: The $\delta^{53 / 52} \mathrm{Cr}$ values of twenty-five geological reference materials (GRMs) were determined including igneous
rocks, coal, shale, stream/ocean sediments and soils, with high-precision double spike MC-ICP-MS (Neptune Plus). Previously
measured GRMs, including MUH-1, OKUM, DTS-2B, and JB-3, were used to monitor the long-term analytical precision and
accuracy. The resulting method yielded a long-term precision of $\leq 0.06 \%$ based
on these GRMs, and the $\delta^{53 / 52} \mathrm{Cr}$ values were excellently consistent with their
previously reported values. Most of the seventeen new GRMs reported here
yielded $\delta^{53 / 52} \mathrm{Cr}$ values within a narrow range from $-0.20 \%$ to $0.01 \%$, with an
average of $-0.14 \pm 0.10 \%$ o( $2 \mathrm{SD})$, which was the same as the unfractionated Bulk
Silicate Earth (BSE). However, SCO-2 (shale) yielded a $\delta^{53 / 52} \mathrm{Cr}$ value of 0.19
$0.03 \%$ ( $2 \mathrm{SD})$ and GBW07334 (ocean sediment) yielded a $\delta^{53 / 52} \mathrm{Cr}$ value of 0.01
$\pm 0.05 \%$ (2SD), which were different from the $\mathrm{BSE}$. Thus, $\mathrm{SCO}-2$ and JH-1 $(-$
$0.20 \pm 0.02 \%$ ) can serve as good candidate GRMs for interlaboratory
comparisons.

\section{INTRODUCTION}

Chromium $(\mathrm{Cr})$ exists in the natural environment mainly as two valence states $\left(\mathrm{Cr}^{3+}\right.$ and $\left.\mathrm{Cr}^{6+}\right)$, and it has four stable isotopes $\left({ }^{50} \mathrm{Cr}\right.$, ${ }^{52} \mathrm{Cr},{ }^{53} \mathrm{Cr}$ and ${ }^{54} \mathrm{Cr}$, Laeter et al., 2003). ${ }^{1}$ Because of the short halflife of ${ }^{53} \mathrm{Mn}$ decaying to ${ }^{53} \mathrm{Cr}(3.7 \pm 0.4 \mathrm{Ma})$, radiogenic ${ }^{53} \mathrm{Cr}$ was used as an astronomical chronometer to identify the evolutionary processes of the early solar system (Götz and Heumann, 1988). ${ }^{2}$ With the development and improvement of multiple-collector inductively couple plasma mass spectrometry (MC-ICP-MS), the measured precision of $\mathrm{Cr}$ isotope compositions has been improved to $\sim 0.02 \%$ o (2SD) ${ }^{2-6}$ and stable $\mathrm{Cr}$ isotopic fractionation in terrestrial sample can be identified. Since $\mathrm{Cr}$ is a redox-sensitive element, and the redox transformation between $\mathrm{Cr}$ (III) and $\mathrm{Cr}$ (VI) can result in 7.6\% $\mathrm{Cr}$ isotopic variation. ${ }^{7,8}$ Therefore, $\mathrm{Cr}$ isotopes have been used to reconstruct the redox conditions of the paleoocean and atmosphere. ${ }^{10,11}$ In addition, Cr (VI) is a soluble, carcinogenic, and common toxic contaminant in modern environments due to its extensive use in many industries such as electroplating and leather tanning. ${ }^{12-14}$ In contrast, $\mathrm{Cr}$ (III) is less soluble and toxic. Thus, an effective way of remediating $\mathrm{Cr}$ (VI) pollution is to reduce $\mathrm{Cr}$ (VI) to $\mathrm{Cr}$ (III). Because heavier $\mathrm{Cr}$ isotopes preferentially stay in the remaining $\mathrm{Cr}(\mathrm{VI}){ }^{7},{ }^{53} \mathrm{Cr} /{ }^{52} \mathrm{Cr}$ ratio can be used to indicate and quantify the extent of $\mathrm{Cr}$ (VI) reduction in contaminated groundwater systems ${ }^{14-18}$. High precision and accuracy data are a prerequisite for applying $\mathrm{Cr}$ isotopes to solve the abovementioned problems.

Geological reference materials (GRMs) play an important role in calibrating analytical methods for quality assurance and interlaboratory comparisons. ${ }^{19,20}$ For Cr isotopes, commonly used GRMs include JP-1 (Peridotite), ${ }^{3,21-23}$ BHVO-2 (Basalt), ${ }^{24,25}$ JDo1 (Carbonatite), ${ }^{26,27}$ and SRG-1b (Shale). ${ }^{23}$ SDO-1 was a shale standard for $\mathrm{Cr}$ isotopes but it has been discontinued. In addition, very few GRMs for environmental and ultramafic samples have been reported. ${ }^{5,6,23}$ Recent studies suggested that the stable $\mathrm{Cr}$ isotope system has a great potential in identifying the pollution sources of stream sediments, and it could be utilized as a proxy for 
oxygen fugacity to study planetary differentiation and magmatic evolution. ${ }^{28,29}$ Hence, the $\mathrm{Cr}$ isotopic ratios of more GRMs with different lithologies need to be further determined.

In this study, the $\mathrm{Cr}$ isotopic ratios of twenty-five, including ultramafic rocks, coal, shale, soil, stream and ocean sediment, were measured by double-spike MC-ICP-MS. Among them, eight GRMs have been published previously and were used to validate our methods, and eighteen samples were reported for the first time. The aim for this work is to expand the data set (data set is 2 words) of $\mathrm{Cr}$ isotopic values in GRMs for interlaboratory comparisons when measuring a wide range of geological and environmental samples.

\section{EXPERIMENTAL}

Reagents and materials. The $\mathrm{HNO}_{3}, \mathrm{HCl}$ and $\mathrm{HF}$ (optima-grade) were purchased from Beijing Institute of Chemical Reagents and distilled with Savillex ${ }^{\mathrm{TM}}$ (USA) DST-1500 stills before using in sample chemical purification. Ultrapure water $\left(18.2 \mathrm{M} \Omega \cdot \mathrm{cm}^{-1}\right.$ resistivity) was obtained from a Milli-Q Element system (Millipore, USA). High-purity reagents, such as $\left(\mathrm{NH}_{4}\right)_{2} \mathrm{~S}_{2} \mathrm{O}_{8}$ (99.8\%), $\mathrm{NH}_{3} \cdot \mathrm{H}_{2} \mathrm{O}(99.999 \%), \mathrm{NH}_{2} \mathrm{OH} \cdot \mathrm{HCl}(99.995 \%)$ and $35 \%$ $\mathrm{H}_{2} \mathrm{O}_{2}$ (guarantee reagent), were purchased from Alfa Aesar (China). Cation and anion exchange resins (AG50W-X8, 200400m; AG1-X8, 100-200m and 200-400m) and polypropylene columns (10ml; same for others) were obtained from Bio-Rad (China). All PFA beakers, tubes and pipette tips were acid-cleaned and air-dried in a class 100 hood, following procedures in Zhu et al. ${ }^{23}$ The double-spike $\left({ }^{50} \mathrm{Cr}-{ }^{54} \mathrm{Cr}\right)$ used in this work was the same as that in Zhu et al. ${ }^{23}$

Twenty-six GRMs were measured in this study. Peridotite (JP1, PCC-1 and DTS-2b), basalt (BRP-1), shale (SCO-2), and coal (CLB-1) were obtained from the United States Geological Survey (USGS). Gabbro (JGB-1,2), basalt (JB-3), and hornblendite (JH1) were purchased from the Geological Survey of Japan (GSJ) (City). Ultramafic rock (MUH-1) and Komatiite (OKUM) were bought from International Association of Geoanalysts (IAG) (UK). Ocean and stream sediments (GBW07325, -31, -34, -35, GSD-1, $4,8,14,16,19)$ and soils (GSS-19, 20, 21) were obtained from the Institute of Geophysical and Geochemical Exploration (IGGE), China.

Sample digestion. The digestion method for various samples were described in detail in Zhu et al. ${ }^{23}$ Briefly, igneous rock samples, including peridotite, basalt, gabbro and rhyolite, were digested in $15 \mathrm{ml}$ PFA beakers. Approximately $50 \mathrm{mg}$ of powdered samples were mixed with $3 \mathrm{ml} \mathrm{HNO} 3-\mathrm{HF}$ (1:2) and decomposing for $8-12 \mathrm{~h}$ at $150{ }^{\circ} \mathrm{C}$ degrees. Dried samples were then treated with $4 \mathrm{ml}$ Aqua regia $(1: 3)\left(\mathrm{HNO}_{3} / \mathrm{HCl}\right.$ for $6-12 \mathrm{~h}$ at $130{ }^{\circ} \mathrm{C}$ and then dried; this process was repeated until no solid residue was observed in the dissolved solution. Other samples, including soils, coal, ocean and stream sediment, were digested with customized high-pressure bombs: $\sim 100 \mathrm{mg}$ of powdered samples was mixed with $3 \mathrm{ml} \mathrm{HNO}_{3}-\mathrm{HF}(4: 1)$ and heated for $36 \mathrm{~h}$ at $185 \pm 5^{\circ} \mathrm{C}$. The digestion procedures were repeated again for completely dissolving samples. All the digested samples were dissolved in $2 \mathrm{M}$ $\mathrm{HNO}_{3}$ mixed with $0.5 \%$ (V/V) $\mathrm{H}_{2} \mathrm{O}_{2}$ for storage.

Chromatographic separation. The chemical purification of all samples was conducted in a class 100 hood at the Isotope Geochemistry Laboratory of China University of Geosciences, Beijing. Following previous procedures. ${ }^{23}$ Briefly, ${ }^{50} \mathrm{Cr}-{ }^{54} \mathrm{Cr}$ double spike was mixed with sample solution before separation in order to correct for potential isotope fractionations during chemical purification and isotope measurement. According to the optimized ${ }^{54} \mathrm{Cr}_{\text {spike }}{ }^{52} \mathrm{Cr}_{\text {sample }}$ ratio of 0.4 , sample solutions containing $600 \mathrm{ng} \mathrm{Cr}$ were spiked with suitable amount of doublespike. The sample-spike mixtures were sealed in $15 \mathrm{ml}$ PFA beaker and heated for over $6 \mathrm{~h}$ at $100{ }^{\circ} \mathrm{C}$ to achieve isotopic equilibrium between sample and spike. The chemical purification scheme described in Zhu et al. ${ }^{23}$ was used to separate $\mathrm{Cr}$ from the sample matrices. Briefly, the samples were successively passed through 2 $\mathrm{ml}$ AG50W-X8 (200-400 $\mathrm{m}$ ) resin and $2 \mathrm{ml} \mathrm{AG1-X8} \mathrm{(100-200} \mathrm{m)}$ resin to remove $\mathrm{Ca}, \mathrm{Fe}$ and some other matrix elements in step I. Step II was used to remove Ti and $\mathrm{V}$ by passing thought $1 \mathrm{ml}$ AG1X8 (200-400m) resin. Chromium was separated from residual matrices during step III, where Cr (III) was oxidized to $\mathrm{Cr}$ (VI) by a strong oxidant Ammonium persulfate $\left(\left(\mathrm{NH}_{4}\right)_{2} \mathrm{~S}_{2} \mathrm{O}_{8}\right)$ at circumneutral $\mathrm{pH}\left(\mathrm{pH}=5.9\right.$, adjusted with $\left.\mathrm{NH}_{3} \cdot \mathrm{H}_{2} \mathrm{O}\right)$. After oxidation, samples were centrifuged, and the supernatants were passed through columns charged with 2ml AG1-X8 (100-200m) resin. High-purity $\mathrm{Cr}$ was eluted from the column by $8 \mathrm{ml} 2 \mathrm{M}$ $\mathrm{HNO}_{3}$ with $0.5 \% \mathrm{H}_{2} \mathrm{O}_{2}$. Cr eluents were evaporated at $130{ }^{\circ} \mathrm{C}$ and redissolved in $2 \% \mathrm{HNO}_{3}$ and diluted to $25 \mu \mathrm{g} \mathrm{L}^{-1}$ for $\mathrm{Cr}$ isotope measurement.

Table 1. Instrument Parameters

\begin{tabular}{|c|c|}
\hline Parameters & Values \\
\hline Cup configuration & $\begin{array}{l}\mathrm{L}^{49}(\mathrm{Ti}), \mathrm{L}^{50}(\mathrm{Ti}, \mathrm{V}, \mathrm{Cr}), \mathrm{L}^{51}(\mathrm{~V}), \\
\mathrm{C}^{52}(\mathrm{Cr}), \mathrm{H} 1^{53}(\mathrm{Cr}), \mathrm{H} 2^{54}(\mathrm{Fe}, \mathrm{Cr}), \\
\mathrm{H} 4^{56}(\mathrm{Fe})\end{array}$ \\
\hline \multicolumn{2}{|l|}{ Inlet system } \\
\hline Cool gas & $15.1 \sim 15.7 \mathrm{~L} / \mathrm{min}$ \\
\hline Auxiliary gas & $1.3 \mathrm{~L} / \mathrm{min}$ \\
\hline Sample gas & $0.91 \sim 1.10 \mathrm{~L} / \mathrm{min}$ \\
\hline RF power & $1250 \mathrm{~W}$ \\
\hline Cones & $\begin{array}{l}\mathrm{H} \text { type (sample), } \mathrm{X} \text { type } \\
\text { (skimmer) }\end{array}$ \\
\hline $\begin{array}{l}\text { Resolution mode } \\
\text { Aridus II systems }\end{array}$ & Medium $M / \Delta M \geq 6500$ \\
\hline Spay chamber temperatures & $110^{\circ} \mathrm{C}$ \\
\hline Desolvator temperatures & $160^{\circ} \mathrm{C}$ \\
\hline Ar sweep gas & $5.1 \sim 6.3 \mathrm{~L} / \mathrm{min}$ \\
\hline Nitrogen gas & No \\
\hline Sample uptake & $110 \mu \mathrm{L} / \mathrm{min}$ \\
\hline Sensitivity ( ${ }^{52} \mathrm{Cr}$ ) & $\geq 300 \mathrm{~V} / \mu \mathrm{g} \mathrm{mL}^{-1}$ \\
\hline
\end{tabular}




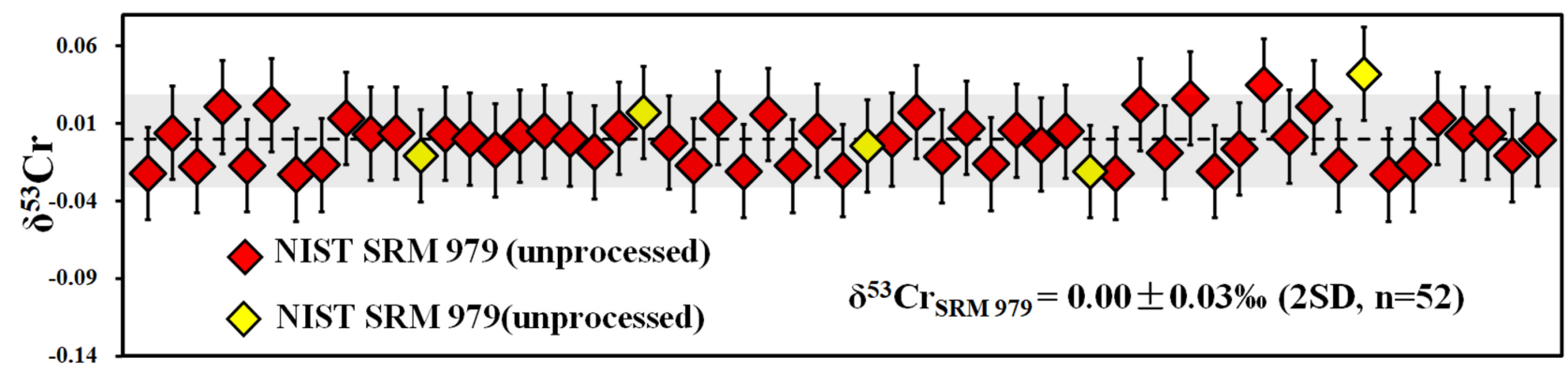

Fig. 1 The intermediate precision of $\delta^{53} \mathrm{Cr}$ for NIST SRM 979.

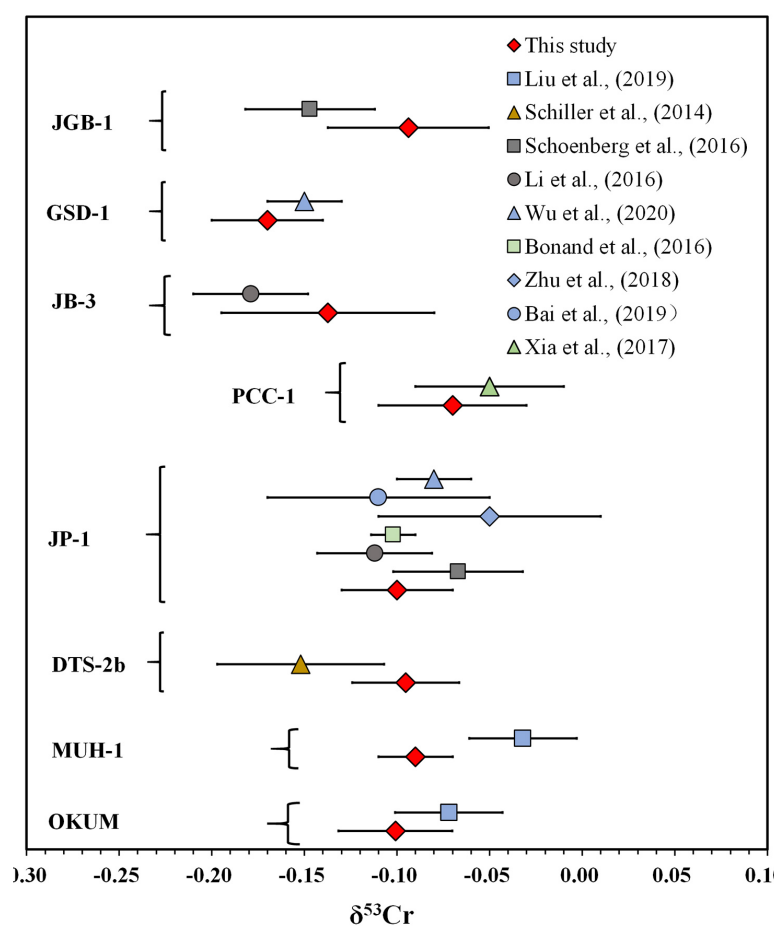

Fig. $2 \delta^{53} \mathrm{Cr}$ values in selected geological reference materials measured in this work versus previous studies.

Mass spectrometry. The measurement of $\mathrm{Cr}$ isotope ratios was conducted on a Thermo Fisher Scientific (USA) Neptune Plus MC-ICP-MS at the Isotope Geochemistry Laboratory, China University of Geosciences, Beijing. The instrument was equipped with 9 Faraday cups connected to $10^{11} \Omega$ amplifiers. Among them, seven faraday cups L3, L2, L1, C, H1, H2 and H4 were used to detect the signal intensities of ${ }^{49} \mathrm{Ti},{ }^{50} \mathrm{Cr},{ }^{51} \mathrm{~V},{ }^{52} \mathrm{Cr},{ }^{53} \mathrm{Cr},{ }^{54} \mathrm{Cr}$ and ${ }^{56} \mathrm{Fe}$ in the static mode. A customized Aridus II (Teledyne CETAC, USA) with a $110 \mu \mathrm{L} \mathrm{min}^{-1}$ micro-concentric PFA nebulizer (ESI, USA) was used to introduce sample solutions into the instrument. ${ }^{6,23}$ Other operating parameters for measuring $\mathrm{Cr}$ isotope are listed in Table 1.

As presented in our previously referenced work, ${ }^{23}$ all isotopes were measured in the medium resolution mode to avoid polyatomic interferences, such as ${ }^{40} \mathrm{Ar}^{12} \mathrm{C}^{+}$and ${ }^{40} \mathrm{Ar}^{14} \mathrm{~N}^{+}$on ${ }^{52} \mathrm{Cr}^{+}$ and ${ }^{54} \mathrm{Cr}^{+}$, respectively. Each analysis consists of three blocks of 60 cycles, each cycle with $4.19 \mathrm{~s}$ integration time and $3 \mathrm{~s}$ idle time. Before each sample/standard analysis, the sample introduction system was washed with $2 \% \mathrm{HNO}_{3}(\mathrm{~V} / \mathrm{V})$ until the signal intensity of ${ }^{52} \mathrm{Cr}$ and ${ }^{54} \mathrm{Cr}$ dropped to less than $3 \mathrm{mV}$. On-Peak- Zero (OPZ) was used to subtract the contribution of blank signal and background noise from sample signals. All data were reported relative to SRM 979: $\delta^{53} \mathrm{Cr}=\left[\left({ }^{53} \mathrm{Cr} /{ }^{52} \mathrm{Cr}\right)_{\text {sample }} /\left({ }^{53} \mathrm{Cr} /{ }^{/ 2} \mathrm{Cr}\right)\right.$ SRM 979$1] \times 1000$. The analysis of every three or four samples were bracketed by spiked SRM 979 with similar Cr concentrations to monitor the instrument stability. The $\delta^{53} \mathrm{Cr}$ values of SRM 979 were used to normalize the sample values: $\delta^{53} \mathrm{Cr}=\delta^{53} \mathrm{Cr}_{\text {sample }}-$ $\delta^{53} \mathrm{Cr}$ SRM $979 .{ }^{23}$

\section{RESULTS AND DISCUSSION}

\section{Blank contributions}

The total procedural $\mathrm{Cr}$ blank, including sample digesting and chemical purification, ranged from 0.7 to $1.2 \mathrm{ng}$ with an average value of $\sim 1.0 \mathrm{ng}$, which was within the range of previous studies (0.12 17 ng). ${ }^{4,26,31,32}$ Our previous study demonstrated that the blank has negligible effects on measured sample $\delta^{53} \mathrm{Cr}$ values when the procedural blank is less than $0.4 \%$ of load $\mathrm{Cr}$ size. ${ }^{26} \mathrm{In}$ this study, Cr blank was less than $0.2 \%$ of the load $\mathrm{Cr}$ mass.

\section{Precision and Accuracy}

The SRM 979 and several GRMs were repeatedly measured to assess the precision and accuracy of the reported method. Spiked SRM 979s were measured 57 times during two analytical sessions separated by 6 months. The two-standard deviation (2SD) of these results was $0.03 \%$ (Fig. 1), which was similar to previous studies. $^{25,}$ 26,31,33 GRMs including GSD-1, JB-3, JGB-1, JP-1, DTS-2b, MUH-1, and OKUM were repeatedly digested, purified and measured in different analytical procedures, with 2SDs ( $\mathrm{n}=4$ 7) of $0.03 \%, 0.02 \%, 0.03 \%$, $0.03 \%$, $0.03 \%, 0.02 \%$, and $0.04 \%$, respectively, which are consistent with values reported, ${ }^{6,21,22,28,34}$ demonstrating that the long-term precision of $\delta^{53} \mathrm{Cr}$ measurement for actual samples was better than $0.06 \%$.

As show in Fig. 2, the mean $\delta^{53} \mathrm{Cr}$ values of SRM 979, GSD-1, JB-3, JGB-1, DTS-2b, MUH-1 and OKUM were $0.00 \pm 0.03 \%$ 
(2SD, $\mathrm{n}=57),-0.17 \pm 0.03 \%$ о (2SD, $\mathrm{n}=4),-0.14 \pm 0.02 \%$ ( $2 \mathrm{SD}$, $\mathrm{n}=4),-0.09 \pm 0.03 \%$ o ( $2 \mathrm{SD}, \mathrm{n}=4),-0.10 \pm 0.03 \%$ o (2SD, $\mathrm{n}=4),-0.09$ $\pm 0.02 \%$ o ( $2 \mathrm{SD}, \mathrm{n}=7),-0.10 \pm 0.04 \%$ o ( $2 \mathrm{SD}, \mathrm{n}=4)$ respectively, which agree with previous works, $5,6,21,22,33$ confirming that the data presented in this study have high precision and accuracy.

\section{Chromium isotope composition in geological reference materials}

The $\delta^{53} \mathrm{Cr}$ of seventeen reference materials were reported for the first time. Their $\delta^{53} \mathrm{Cr}$ values ranged from $-0.20 \%$ to $0.19 \%$ (Table 2). Based on lithology, these GRMs were divided into five groups (igneous rock, stream sediments, ocean sediments, soils, and sedimentary rocks), which will be discussed in following sections.

(i) Igneous rock reference materials. $\mathrm{JH}-1$ yielded a $\delta^{53} \mathrm{Cr}$ value of $-0.20 \pm 0.02 \%$ ( $2 \mathrm{SD}, \mathrm{n}=4)$. This is the first $\delta^{53} \mathrm{Cr}$ for a hornblendite GRM. The $\delta^{53} \mathrm{Cr}$ value was similar to other ultramafic GRMs, such as PCC-1 $(-0.05 \pm 0.04 \% \text { o })^{21}$, JP-1 ( -0.05 $\pm 0.04 \% 0),{ }^{26}$ and DTS-2b $(-0.15 \pm 0.04 \% 0)^{33}$. The $\delta^{53} \mathrm{Cr}$ of JGB-2 (gabbro) was $-0.17 \pm 0.03 \%$ o ( $2 \mathrm{SD}, \mathrm{n}=4)$, which was identical to JGB-1 (gabbro, $-0.15 \pm 0.04 \%$ ) $^{32}$ and W-2 (diabase, $-0.22 \pm$ $0.04 \%$ \%). ${ }^{4}$ The $\delta^{53} \mathrm{Cr}$ of BRP-1 was $-0.12 \pm 0.02 \%$ ( $\left.2 \mathrm{SD}, \mathrm{n}=4\right)$, similar to other basalt reference materials such as BHVO-2 (-0.11 $\pm 0.08 \% 0),{ }^{24}$ BCR-2 $(-0.11 \pm 0.05 \%),{ }^{26}$ and BIR-1 (-0.18 \pm $0.05 \%) .{ }^{22}$ These data fall within the $\delta^{53} \mathrm{Cr}$ range of mantle xenoliths, ultramafic and mafic rocks $(-0.22 \%$ to $0.06 \%$, with a mean of $-0.08 \pm 0.16 \%$, $\mathrm{n}=64),{ }^{32,34,35,36}$ consistent with the conclusion that $\delta^{53} \mathrm{Cr}$ variation in high temperature magmatic processes is small. ${ }^{24,32}$

(ii) Sediment reference materials. Six stream sediments were collected in different river basins of China, including various igneous and sedimentary rock areas, polymetallic areas, copper nickel mining area, carbonate weathering areas and Tibet plateau. The $\delta^{53} \mathrm{Cr}$ values of these samples vary narrowly within the range of $-0.20 \%$ to $-0.04 \%$, suggesting that there is insignificant $\mathrm{Cr}$ isotopic variation in stream sediments collected from both mining area and natural background area. Stream sediments have been used to establish the chemical compositions of the upper continental crust, such as $\mathrm{Pb}$ isotope and $\mathrm{Ba}$ isotope compositions. ${ }^{37,38}$ The mean $\delta^{53} \mathrm{Cr}$ value of stream sediments, measured in this and previous studies ${ }^{6,23,25}$, is $-0.13 \pm 0.13 \%$ ( $2 \mathrm{SD}$, $\mathrm{n}=20$ ), similar to the $\mathrm{Cr}$ isotope composition of the upper continental crust $(-0.10 \pm 0.10 \%)^{23}$ and bulk silicate earth (-0.124 $\pm 0.10 \%$ o..$^{32}$

Many ocean sediments have been measured in previous studies with large $\mathrm{Cr}$ isotope variations (-0.14 \%o to $0.92 \%$ o). ${ }^{39,40,41}$ GBW07334 and GBW07335 collected in South China ocean yielded $\delta^{53} \mathrm{Cr}$ values of $0.01 \pm 0.05 \%$ ( $\left.2 \mathrm{SD}, \mathrm{n}=4\right)$ and $-0.04 \pm 0.06 \%$ ( $2 \mathrm{SD}, \mathrm{n}=4$ ), respectively. According to the redox conditions of the sedimentary environment, previously reported marine sediment samples can be divided into three groups: Anoxic, hypoxic and oxic, with contrasting average $\delta^{53} \mathrm{Cr}$ values of $0.30 \pm 0.11 \%$ (2SD, $\mathrm{n}=21)^{39,40}, 0.60 \pm 0.28 \%$ (2SD, $\left.\mathrm{n}=63\right),{ }^{40,41}$ and $-0.05 \pm 0.11 \%$ (2SD, n=25), ${ }^{40}$ respectively. The $\delta^{53} \mathrm{Cr}$ values of GBW07334 and GBW07335 fall within the range of oxic sediments, consistent with the fact that they were likely deposited in oxic environment.

(iii) Soil reference materials. The $\delta^{53} \mathrm{Cr}$ values of GSS-19, 20, 21 were $-0.11 \pm 0.06 \%$ o ( $2 \mathrm{SD}, \mathrm{n}=4),-0.09 \pm 0.02 \%$ ( $2 \mathrm{SD}, \mathrm{n}=4)$ and $-0.12 \pm 0.06 \%$ ( $2 \mathrm{SD}, \mathrm{n}=4)$, respectively. Taking previously reported soil samples into consideration, ${ }^{6,23}$ the average $\delta^{53} \mathrm{Cr}$ of soils is estimated to be $-0.10 \pm 0.33 \%$ o $(2 \mathrm{SD}, \mathrm{n}=17)$. Soil is the residual product of chemical weathering of parent rocks, many processes can lead to $\mathrm{Cr}$ isotope fractionation during weathering, such as oxidation of $\mathrm{Cr}$ (III) to $\mathrm{Cr}(\mathrm{VI})^{42,43}$ and/or adsorption of $\mathrm{Cr}$ (VI) by biomaterials. ${ }^{44}$ Published $\delta^{53} \mathrm{Cr}$ values for soil profile samples range from $-0.57 \%$ to $0.23 \%{ }^{25,42,44}$ and our soil $\delta^{53} \mathrm{Cr}$ data are within this range.

(iv) Shale and coal reference materials. The $\delta^{53} \mathrm{Cr}$ of SCO-2 was $0.19 \pm 0.03 \%$ o ( $2 \mathrm{SD}, \mathrm{n}=4)$, which is within the range of other previously published shale reference materials, such as SGR-1b $(0.30 \pm 0.06 \%)^{23}$ and SDO-1 $(-0.08 \pm 0.05 \% \text { o })^{32}$, and GSR-5 ($0.15 \pm 0.03 \%$ ). ${ }^{6}$ The total range of $\delta^{53} \mathrm{Cr}$ in published shale GRMs is relatively small with $0.45 \%$, which may be due to varying redox states for their deposition environments. The $\delta^{53} \mathrm{Cr}$ of CLB-1 was $-0.09 \pm 0.04 \%$ o ( $2 \mathrm{SD}, \mathrm{n}=8)$, which was the first coal reference material published so far for $\mathrm{Cr}$ isotopes.

\section{CONCLUSIONS}

The $\delta^{53} \mathrm{Cr}$ of twenty-five GRMs were measured using doublespike MC-ICP-MS. Repetitive digestion, purification and measurements yielded a precision of less than $0.06 \%$ (2SD), similar to previous studies. Eight of these GRMs have been measured previously, and the measured values are consistent with reported values, confirming the high-precision and accuracy of the generated data. The $\delta^{53} \mathrm{Cr}$ of seventeen new GRMs were reported for the first time, $\delta^{53} \mathrm{Cr}$ values ranging between $-0.20 \%$ and $0.19 \%$. Among the investigated GRMs, GBW07334 (0.01 \pm $0.05 \%$ ), JH-1 (-0.20 $\pm 0.02 \%$ ), and SCO-2 (0.19 $\pm 0.03 \%$ ) are slightly different from the unfractionated BSE, and thus are good candidate reference materials for interlaboratory comparisons.

\section{AUTHOR INFORMATION}

\section{Corresponding Author}

*J.-M. Zhu

Email address: jmzhu@cugb.edu.cn

\section{Notes}

The authors declare no competing financial interest. 
Table 2 Cr Isotopic Composition of Geological Standards in this Study and in the Literature

\begin{tabular}{|c|c|c|c|c|c|c|c|}
\hline Sample & Sample type & Reference & $\operatorname{Cr}(\mu g / g)^{a}$ & $\delta^{53} \operatorname{Cr}(\%)$ & 2SD & $\mathbf{n}^{\mathrm{b}}$ & $\mathbf{U}^{\mathrm{c}}$ \\
\hline \multirow[t]{4}{*}{ OKUM (IAG) } & Komatiite & This study & 2301 & -0.10 & 0.03 & 4 & \\
\hline & & & & -0.10 & 0.04 & 4 & \\
\hline & & Average & & -0.10 & 0.04 & 8 & 0.02 \\
\hline & & Liu et al., (2019) & 2385 & -0.07 & 0.025 & 3 & \\
\hline \multirow[t]{2}{*}{ MUH-1 (IAG) } & Ultramafic rock & This study & 2080 & -0.09 & 0.02 & 4 & 0.03 \\
\hline & & Liu et al., (2019) & & -0.032 & 0.029 & 3 & \\
\hline \multirow[t]{2}{*}{ DTS-2b (USGS) } & Peridotite & This study & 21250 & -0.10 & 0.03 & 4 & 0.03 \\
\hline & & Schiller et al., (2014) & & -0.152 & 0.045 & 4 & \\
\hline \multirow[t]{2}{*}{ PCC-1 (USGS) } & Peridotite & This study & 3769 & -0.07 & 0.04 & 4 & 0.02 \\
\hline & & Xia et al., (2017) & 2727 & -0.05 & 0.04 & & \\
\hline \multirow[t]{7}{*}{ JP-1 (GSJ) } & Peridotite & This study & 2894 & -0.10 & 0.03 & 4 & 0.02 \\
\hline & & Schoenberg et al., (2016) & & -0.067 & & & \\
\hline & & Li et al., (2016) & & -0.112 & & & \\
\hline & & Bonand et al., (2016) & & -0.102 & 0.012 & & \\
\hline & & Zhu et al., (2018) & 2800 & -0.05 & 0.06 & 3 & \\
\hline & & Bai et al., (2019) & & -0.11 & 0.03 & 9 & \\
\hline & & Wu et al., (2020) & & -0.08 & 0.02 & 4 & \\
\hline JH-1 (GSJ) & Hornblendite & This study & 576 & -0.20 & 0.02 & 4 & 0.02 \\
\hline \multirow[t]{2}{*}{ JGB-1 (GSJ) } & Gabbro & This study & 52.3 & -0.09 & 0.03 & 4 & 0.03 \\
\hline & & Schoenberg et al., (2016) & 52.5 & -0.147 & & & \\
\hline JGB-2 (GSJ) & Gabbro & This study & 125 & -0.17 & 0.03 & 4 & 0.02 \\
\hline JB-3 (GSJ) & Basalt & This study & 50.1 & -0.14 & 0.02 & 4 & 0.02 \\
\hline 130 & & Li et al., (2016) & & -0.17 & & 3 & \\
\hline BRP-1 (USGS) & Basalt & This study & 10.9 & -0.12 & 0.02 & 4 & 0.01 \\
\hline SCO-2 (USGS) & Shale & This study & 40.3 & 0.19 & 0.03 & 4 & 0.02 \\
\hline \multirow[t]{2}{*}{ GSD-1 (IGGE) } & Stream sediment & This study & 189 & -0.17 & 0.03 & 3 & 0.02 \\
\hline & & Wu et al., (2020) & & -0.16 & 0.02 & 5 & \\
\hline \multirow[t]{3}{*}{ GSD-4 (IGGE) } & Stream sediment & This study & 99.8 & -0.19 & 0.03 & 3 & \\
\hline & & & & -0.18 & 0.02 & 3 & \\
\hline & & Average & & -0.19 & 0.03 & 6 & 0.02 \\
\hline GSD-8 (IGGE) & Stream sediment & This study & 7.88 & -0.16 & 0.03 & 3 & 0.03 \\
\hline GSD-14 (IGGE) & Stream sediment & This study & 229 & -0.20 & 0.06 & 3 & 0.02 \\
\hline GSD-16 (IGGE) & Stream sediment & This study & 20.5 & -0.17 & 0.04 & 3 & 0.02 \\
\hline GSD-19 (IGGE) & Stream sediment & This study & 77.2 & -0.16 & 0.03 & 3 & 0.03 \\
\hline GBW07325 (IGGE) & Stream sediment & This study & 40.3 & -0.11 & 0.04 & 4 & 0.03 \\
\hline GBW07331 (IGGE) & Stream sediment & This study & 62.3 & -0.04 & 0.06 & 3 & 0.07 \\
\hline GBW07334 (IGGE) & Ocean sediment & This study & 64.1 & 0.01 & 0.05 & 3 & 0.05 \\
\hline GBW07335(IGGE) & Ocean sediment & This study & 77.4 & -0.04 & 0.06 & 3 & 0.05 \\
\hline GSS-19 (IGGE) & Soil & This study & 51.2 & -0.11 & 0.06 & 4 & 0.05 \\
\hline GSS-20 (IGGE) & Soil & This study & 45.2 & -0.09 & 0.02 & 4 & 0.01 \\
\hline GSS-21 (IGGE) & Soil & This study & 57.2 & -0.12 & 0.06 & 4 & 0.05 \\
\hline \multirow[t]{3}{*}{ CLB-1 (IGGE) } & Coal & This study & 10.1 & -0.09 & 0.05 & 4 & \\
\hline & & & & -0.09 & 0.03 & 4 & \\
\hline & & Average & & -0.09 & 0.04 & 8 & 0.02 \\
\hline
\end{tabular}

a The Cr concentrations were calculated using double-spike method, Lu et al., (in press) presented the method in detail.

b The Number of analyses.

c The value was calculated from $95 \%$ confidence interval of independent replicate analyses that take the student- $t$ distribution into account.

\section{ACKNOWLEDGMENTS}

This work was funded by the National Natural Science Foundation of China (U1612441 and 41673017), and MOST Special Fund from the State Key Laboratory of Geological Processes and Mineral Resources, China University of Geosciences (MSFGPMR201812 and 201814).

\section{REFERENCES}

1. J. R. Laeter, J. K. Böhlke, P. De.Bièvre, H. Hidaka, H. S. Peiser, K. J. R. Rosman, and P. D. P. Taylor, Pure Appl. Chem., 2014, 75, 683-800. https://dx.doi.org/10.1351/pac200375060683

2. G. Adolf and G. Klaus, Int. J. Mass Spectrom. Ion Phys., 1988, 83, 319-330. https://doi.org/10.1016/0168-1176(88)80036-3

3. P. Bonnand, R. H. James, I. J. Parkinson, D. P. Connelly, and I. J. Fairchild, Earth Planet. Sci. Lett. 2013, 382, 10-20. https://doi.org/10.1016/j.epsl.2013.09.001.

4. C.-F. Li, L.-J. Feng, X.-C. Wang, S.-A. Wilde, Z.-Y. Chu, and 
J.-H. Guo, J. Anal. At. Spectrom., 2017, 32, 1938-1945. https://doi.org/10.1039/c7ja00225d

5. C. Y. Liu, L. J. Xu, C. T. Liu, J. Liu, L. P. Qin, Z. D. Zhang, S. A. Liu, and S. G. Li, Geostand. Geoanal. Res., 2019, 43, 647-661. https://dx.doi.org/10.1111/ggr.12283.

6. G. Wu, J.-M. Zhu, X. Wang, G. Han, D. Tan, and S.-J. Wang, J. Anal. At. Spectrom., 2019, 34, 1639-1651. https://doi.org/10.1039/c9ja00077a

7. A. S. Ellis, T. M. Johnson, and T. D. Bullen, Science, 2002, 295, 2060-2062. https://doi.org/10.1126/science.1068368

8. S. Zink, R. Schoenberg, and M. Staubwasser, Geochim. Cosmochim. Acta, 2010, 74, 5729-5745. https://doi.org/10.1016/j.gca.2010.07.015

9. A. Basu and T.M. Johnson, Environ. Sci. Technol., 2012, 46, 53535360. https://doi.org/10.1021/es204086y

10. R. Frei, C. Gaucher, S. W. Poulton, and D. E. Canfield, Nature, 2009, 461, 250-253. https://doi.org/10.1038/nature08266

11. Planasvsky R. Frei, D. Poiré, and K. M. Frei, Chem. Geology, 2014, 381, 110-124. https://doi.org/10.1016/j.chemgeo.2014.05.015

12. R. E. Cranston and J. W. Murray, Anal. Chim. Acta, 1978, 99, 275282. https://doi.org/10.1016/S0003-2670(01)83568-6

13. J. Robles-Camacho and M. A. Armienta, J. Geochem. Explor, 2000, 68, 167-181.

https://doi.org/10.1016/S0375-6742(99)00083-7

14. J. A. Izbicki, J. W. Ball, T. D. Bullen and S. J. Sutley, Appl. Geochem., 2008, 23, 1325-1352. https://doi.org/10.1016/j.apgeochem.2007.11.015

15. J. A. Izbicki, M. T. Wright, W. A. Seymour, R. B. McCleskey, M. S Fram, K. Belitz, and B. K. Esser, Appl. Geochem., 2015, 63, 203217. https://doi.org/10.1016/j.apgeochem.2015.08.007

16. E. C. Berna, T. M. Johnson, R. S. Makdisi, and A. Basu, Environ. Sci. Technol., 2010, 44,1043-1048. https://doi.org/10.1021/es902280s

17. A. L. Raddatz, T. M. Johnson, and T. L. McLing, Environ. Sci. Technol., 2011, 45, 502-507. https://doi.org/10.1021/es102000z

18. M. Novak, V. Chrastny, O. Sebek, E. Martinkova, E. Prechova, J. Curik, F. Veselovsky, M. Stepanova, B. Dousova, and F. J. A. G. Buzek, Appl. Geochem., 2017, 80, 134-142. https://doi.org/10.1016/j.apgeochem.2017.03.009

19. K. P. Jochum, U. Nohl, K. Herwig, E. Lammel, and A. W. J. G. Hofmann, Geostand. Geoanal. Res., 2005, 29, 333-338 https://doi.org/10.1111/j.1751-908X.2005.tb00904.x

20. L. Yang and R. E. J. A. Sturgeon, Anal. Bioanal. Chem., 2009, 393, 377-385. https://doi.org/10.1007/s00216-008-2348-6

21. R. Schoenberg, A. Merdian, C. Holmden, I. C. Kleinhanns, K. Haßler, M. Wille, and E. Reitter, Geochim. Cosmochim. Acta, 2016, 183, 14-30. https:// doi.org/10.1016/j.gca.2016.03.013

22. C.-F. Li, L.-J. Feng, X.-C. Wang, Z.-Y. Chu, J.-H. Guo and S. A. Wilde, J. Anal. At. Spectrom., 2016, 31, 2375-2383. https://doi.org/10.1039/c6ja00265j

23. J.-M. Zhu, G. Wu, X. Wang, G. Han, and L. Zhang, J. Anal. At. Spectrom., 2018, 33, 809-821. https://doi.org/10.1039/c8ja00033f

24. X. Wang, N. J. Planavsky, C. T. Reinhard, H. Zou, J. J. Ague, Y. Wu, B. C. Gill, E. M. Schwarzenbach, and B. Peucker-Ehrenbrink, Chem. Geology, 2016, 423, 19-33. https://dx.doi.org/10.1016/j.chemgeo.2016.01.003
25. W. Wu, X. Wang, C. T. Reinhard, and N. J. Planavsky, Chem. Geology, 2017, 456, 98-111. https://doi.org/10.1016/j.chemgeo.2017.03.009

26. A. S. Rodler, R. Frei, C. Gaucher, and G. J. B. Germs, Precambrian Res., 2016, 286, 234-249. https://doi.org/10.1016/j.precamres.2016.10.007

27. N. S. Pereira, A. R. Voegelin, C. Paulukat, A. N. Sial, V. P. Ferreira, and R. Frei, Geobiology, 2016, 14, 54-67. https://doi.org/10.1111/gbi.12155

28. X. He, G. Chen, Z. Fang, W. Liang, B. Li, J. Tang, Y. Sun, and L. Qin, Environ. Pollut., 2020, 264, 114686. https://doi.org/10.1016/j.envpol.2020.114686

29. J. Shen, J. Xia, L. Qin, R. W. Carlson, S. Huang, R. T. Helz, and T. D. Mock, Geochim. Cosmochim. Acta, 2020, 278, 289-304 https://doi.org/10.1016/j.gca.2019.10.003

30. P. Bonnand, I. J. Parkinson, R. H. James, A.-M. Karjalainen, and M. A. Fehr, J. Anal. At. Spectrom., 2011, 26, 528-535. https://dx.doi.org/10.1039/c0ja00167h

31. S. Pontér, N. Pallavicini, E. Engström, D. C. Baxter and I. Rodushkin, J. Anal. At. Spectrom., 2016, 31, 1464-1471. https://dx.doi.org/10.1039/c6ja00145a

32. R. Schoenberg, S. Zink, M. Staubwasser and F. von Blanckenburg, Chem. Geology, 2008, 249, 294-306. https://dx.doi.org/10.1016/j.chemgeo.2008.01.009.

33. M. Schiller, J. N. Connelly and M. Bizzarro, Meteorit Planet. Sci., 2017, 52, 1233-1243. https://dx.doi.org/10.1111/maps.12848.

34. J. Shen, J. Liu, L. Qin, S.-J. Wang, S. Li, J. Xia, S. Ke, and J. Yang, Geochem. Geophy. Geosy., 2015, 16, 3840-3854. https://dx.doi.org/10.1002/2015gc005944

35. J. Xia, L. Qin, J. Shen, R. W. Carlson, D. A. Ionov, and T. D. Mock, Earth and Planet. Sci. Lett., 2017, 464, 103-115. https://doi.org/10.1016/j.eps1.2017.01.045

36. C. Chen, B.-X. Su, Y. Xiao, P. A. Sakyi, X.-Q. He, K.-N. Pang, I. Uysal, E. Avc1, and L.-P. Qin, Lithos, 2019, 342-343, 361-369. https:// doi.org/10.1016/j.lithos.2019.05.038

37. R. Millot, C.-J. Allègre, J. Gaillardet, and S. Roy, Chem. Geol., 2004, 203, 75-90. https://doi.org/10.1016/j.chemgeo.2003.09.002

38. X.-Y. Nan, H.-M. Yu, R. L. Rudnick, R. M. Gaschnig, J. Xu, W.-Y. Li, Q. Zhang, Z.-D. Jin, X.-H. Li and F. Huang, Geochim.Cosmochim. Acta, 2018, 233, 33-49. https://doi.org/10.1016/j.gca.2018.05.004

39. C. T. Reinhard, N. J. Planavsky, X. Wang, W. W. Fischer, T. M. Johnson, and T. W. Lyons, Earth Planet. Sci. Lett., 2014, 407, 9-18. https:// doi.org/10.1016/j.epsl.2014.09.024

40. B. Gueguen, C. T. Reinhard, T. J. Algeo, L. C. Peterson, S. G. Nielsen, X. Wang, H. Rowe, and N. J. Planavsky, Geochim. Cosmochim. Acta, 2016, 184, 1-19. https://doi.org/10.1016/j.gca.2016.04.004

41. S. Bruggmann, F. Scholz, R. M. Klaebe, D.E. Canfield, and R. Frei, Geochim. Cosmochim. Acta, 2019, 257, 224-242. https://doi.org/10.1016/j.gca.2019.05.001

42. A. Berger and R. Frei, Geoderma, 2014, 213, 521-532. https://doi.org/10.1016/j.geoderma.2013.09.004

43. J.-L. Feng and C.-F. Li, Geoderma, 2019, 339, 106-114. https://doi.org/10.1016/j.geoderma.2018.12.047

44. H. Šillerová, V. Chrastny, E. Cadkova, and M. Komarek, Chemosphere, 2014, 95, 402-407. https://doi.org/10.1016/j.chemosphere.2013.09.054 